\title{
Remarkable change in age-specific breast cancer incidence in the Swiss canton of Geneva and its possible relation with the use of hormone replacement therapy
}

\author{
Christine Bouchardy*1, Alfredo Morabia ${ }^{2}$, Helena M Verkooijen ${ }^{1}$, \\ Gérald Fioretta ${ }^{1}$, Yves Wespi ${ }^{3}$ and Peter Schäfer ${ }^{4}$
}

Address: ${ }^{1}$ Geneva Cancer Registry, Institute for Social and Preventive Medicine, Geneva University, 55 boulevard de la Cluse, 1205 Geneva, Switzerland, ${ }^{2}$ Division of Clinical Epidemiology, Geneva University Hospitals, 24 rue Micheli-du-Crest, 1211 Geneva 14, Switzerland, ${ }^{3}$ Group of Gynecologists and Obstetricians Geneva, Association of Physicians of the Canton of Geneva, 8, rue Saint-Leger, 1205 Geneva, Switzerland and ${ }^{4}$ Clinic of Gynecology, Senology, Department of Obstetrics and Gynecology, Geneva University Hospitals, 30 boulevard de la Cluse, 1211 Geneva 14 , Switzerland

Email: Christine Bouchardy* - christine.bouchardymagnin@imsp.unige.ch; Alfredo Morabia - a.morabia@hcuge.ch; Helena M Verkooijen - lenny.verkooijen@imsp.unige.ch; Gérald Fioretta - gerald.fioretta@imsp.unige.ch;

Yves Wespi - christine.bouchardymagnin@imsp.unige.ch; Peter Schäfer - peter.schafer@hcuge.ch

* Corresponding author

Published: 22 March 2006

BMC Cancer2006, 6:78 doi:10.1186/1471-2407-6-78

This article is available from: http://www.biomedcentral.com//47/-2407/6/78

(C) 2006Bouchardy et al; licensee BioMed Central Ltd.

This is an Open Access article distributed under the terms of the Creative Commons Attribution License (http://creativecommons.org/licenses/by/2.0), which permits unrestricted use, distribution, and reproduction in any medium, provided the original work is properly cited.
Received: 01 November 2005

Accepted: 22 March 2006

\begin{abstract}
Background: This article aims to explain the reasons for the remarkable change in age of breast cancer occurrence in the Swiss canton of Geneva.

Methods: We used population-based data from the Geneva cancer registry, which collects information on method of detection, stage and tumour characteristics since 1975. For patients diagnosed between 1997-2003, we obtained additional information on use of hormone replacement therapy from a large prospective study on breast cancer. Using generalized log linear regression analysis, we compared age-specific incidence rates with respect to period, stage, oestrogen receptor status, method of detection and use of hormone replacement therapy.
\end{abstract}

Results: In the periods 1975-1979 and 1985-1989, breast cancer risk increased with age, showing the highest incidence rates among women aged $\geq 85$ years. From 1997, the age-specific incidence curve changed completely $(p<0.0001)$, showing an incidence peak at 60-64 years and a reduced incidence among elderly women. This incidence peak concerned mainly early stage and oestrogen positive cancers and was exclusively observed among women who ever used hormone replacement therapy, regardless whether the tumour was screen-detected or not.

Conclusion: The increasing prevalence of hormone replacement therapy use during the 1990s could explain the important change in age-specific breast cancer incidence, not only by increasing breast cancer risk, but also by revealing breast cancer at an earlier age. 


\section{Background}

In Western countries, breast cancer is the most frequent cancer among women and its incidence is still increasing. Several factors have contributed to this increase. Screening mammography temporarily increases incidence by discovering incident, as well as prevalent cases. Higher exposure to breast cancer risk factors, such as low and late parity, alcohol intake and use of hormone replacement therapy (HRT) [1,2] could also explain the incidence increase. It has now been established that HRT represents a true risk factor for breast cancer $[3,4]$. After the publication of the Women's Health Initiative in 2002, a study reporting greater harm than benefit of HRT use [5], HRT use has decreased sharply in Europe and North America $[6,7]$.

The Swiss canton of Geneva has one of the highest incidence rates of breast cancer in the world [8]. Opportunistic mammography screening was started in Geneva at the end of the 1980's and in 1999 an organised mammography screening program was implemented. This program invites all resident women aged from 50 to 69 years every two years to a free mammography with double reading. However, the participation in the organised screening program is low and most women undergo opportunistic screening. The Swiss national Health Survey, performed in 1997 , reported that $66 \%$ of the Geneva women aged $\geq 40$ years had undergone at least one mammography examination [9].

Use of HRT was very common in Geneva where over 50\% of women aged 45-59 years used HRT in 1996 [10].

In this study, we describe changes in age-specific breast cancer incidence in Geneva and examine possible reasons for these changes.

\section{Methods}

We used data from the Geneva cancer registry, which records information on all incident cancer cases that occur in the canton (approximately 420,000 inhabitants). The registration is based on several sources of information and is very accurate, as attested by its low percentage $(<2 \%)$ of cases recorded from death certificates only [8]. All hospitals and pathology laboratories report information on every current and past cancer case to the Geneva cancer registry. Trained tumour registrars systematically abstract missing information and the cancer registry regularly sends special questionnaires to private physicians to secure information on patients treated in the private sector.

For every cancer case, we record sociodemographic characteristics, method of detection of the tumour, tumour characteristics, stage of disease at diagnosis, treatment, survival status, and cause of death.

The study included all 8045 invasive breast cancer cases diagnosed between 1975-2003 among the resident population. Method of detection was categorized as mammography screening vs. other. Stage at diagnosis was based on the Tumour, Node and Metastasis TNM classification system [11]. Stages were classified into three groups: stage I (T0 or T1, N0), stage II (T0 or T1 and N1, $\mathrm{T} 2$ and N0 or N1, T3 and N0), and other stages (T0 or T1 or T2 and N2, T3 and N1 or N2, T4 and any N, any T and $\mathrm{N} 3$, or $\mathrm{M} 1$, and unknown stages). Oestrogen receptor status was categorized as positive if tumours presented oestrogen receptors in $\geq 10 \%$ of the tumour cells.

Additional information on the patient's use of hormone replacement therapy (coded as ever vs. never user) was provided by a large study on risk factors for breast cancer [12]. This study was prospectively collected, by means of personal interviews, information on life style factors of breast cancer patients and control individuals.

This study included 400 breast cancer patients aged 50-74 years, diagnosed between 1997-2000 in the canton of Geneva and they were individually linked to the cancer registry data set. These women represented $46 \%$ of all breast cancer patients in this age group recorded at the cancer registry during the same period.

We calculated age-specific breast cancer incidence rates per 100'000 by five-year age groups for four different periods (1975-1979, 1985-1989, 1997-2000, and 20012003). Differences between age-specific incidence curves were analyzed by generalized log linear regression analysis [13]. We compared age-specific incidence rates among the 400 patients with information on use of HRT dividing them into four groups of patients: 1) ever used HRT, tumour detected by mammography screening $(n=87), 2)$ ever used HRT, tumour not detected by mammography screening $(\mathrm{n}=141), 3)$ never used HRT, tumour detected by mammography screening $(n=53), 4)$ never used HRT, tumour not detected by mammography screening $(\mathrm{n}=$ 119).

\section{Results}

Figure 1 shows the change in breast cancer incidence by age. In the periods 1975-1979 and 1985-1989, breast cancer incidence increased with age. Rates among women aged $\geq 85$ years $(568 / 100 ' 000)$ were at least three times higher than among women aged 50-54 years (182/ 1000 '000). For the period 1997-2000, the age-specific incidence curve was completely different and showed a peak at 60-64 years $\left(488 / 100^{\prime} 000\right)$. In this period, rates among the oldest women (313/100'000) were much 


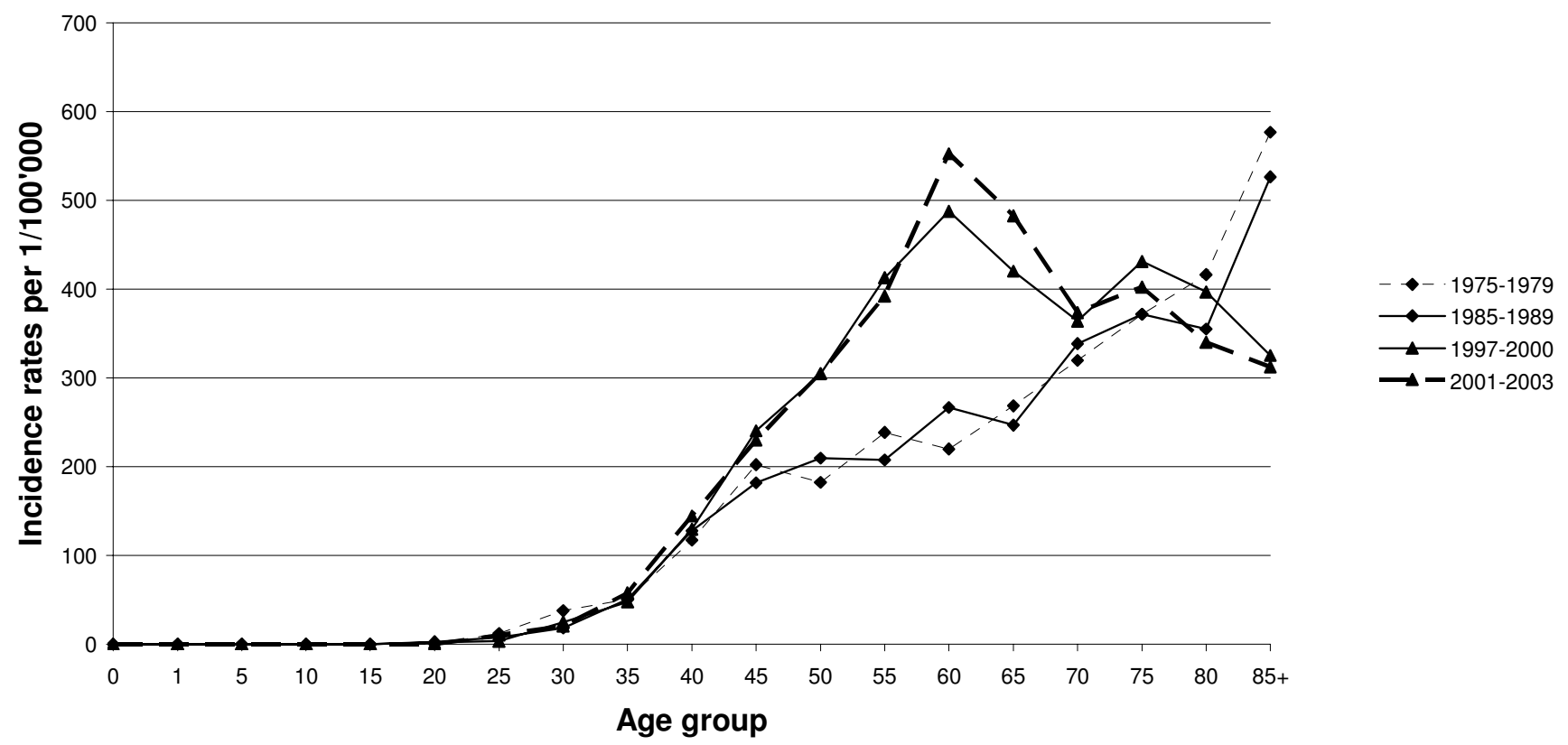

Figure I

Invasive breast cancer incidence rates by age and period, Geneva cancer registry 1975-2003.

lower and comparable to those of women aged 50-54 years $(303 / 100 ' 000)$. Data from the last available period (2001-2003) confirmed the change in incidence rate by age. The incidence peak among women aged $60-64$ years, occurring since 1997, involved mainly early stages (stage I and II) and oestrogen receptor positive tumours (Figure 2 ). Table I compares the patient and tumour characteristics among women aged 60-64 years before and after the change in age-specific incidence. The proportion of stage I disease rose from 32 to $48 \%$ ( $\mathrm{p}<0.001)$. Also, the proportion of women of high social class was much higher in the recent years. The proportion of lobular cancer increased sharply: before the change in incidence pattern, lobular cancer represented only $2 \%$ of the tumours occurring in women aged $60-64$ years, while afterwards, $14 \%$ of women aged 60-64 years presented with lobular histology.

Figure 3 presents incidence rates by age according to the use of HRT and the method of tumour detection among the 400 patients (aged 50-74 years) with available data on HRT. As information on HRT use was available for $46 \%$ of all breast cancer patients, rates were approximately $50 \%$ of the overall breast cancer incidence rates for the period 1997-2000. The age-specific incidence curves were significantly different among ever users of HRT compared with never users $(P<0.0001)$. The incidence peak was observed only among ever users of HRT, regardless whether the tumour was detected by mammography screening or not. For women who never used HRT, there was no incidence peak at 60-64 years.

\section{Discussion}

This study shows a remarkable change in age-specific breast cancer incidence in Geneva. In developed countries, other than Japan, the typical age incidence curve of breast cancer described a progressive increase of risk with age, with a slope down around the menopause age, called the Clemmensen's hook. This typical curve by age is no longer observed in Geneva, where the risk of developing breast cancer does not increase with advancing age anymore. The highest breast cancer risk is now observed among women aged 60-64 years with strongly decreased risks among older women. The incidence peak of women aged 60-64 years was only observed in early stage disease and in oestrogen receptor positive tumours. In the subgroup of women for whom information on HRT use and mammography screening was available, the incidence peak was only present among women who ever used HRT.

The prevalence of screening and HRT use are high in our study population and we had the opportunity to examine the respective effects of each of these factors on the change in age of breast cancer occurrence. However, we realise that our study has several shortcomings. Information on HRT use was available only for approximately $50 \%$ of the women diagnosed in the period 1997-2000. Although these women were recruited in the context of a popula- 

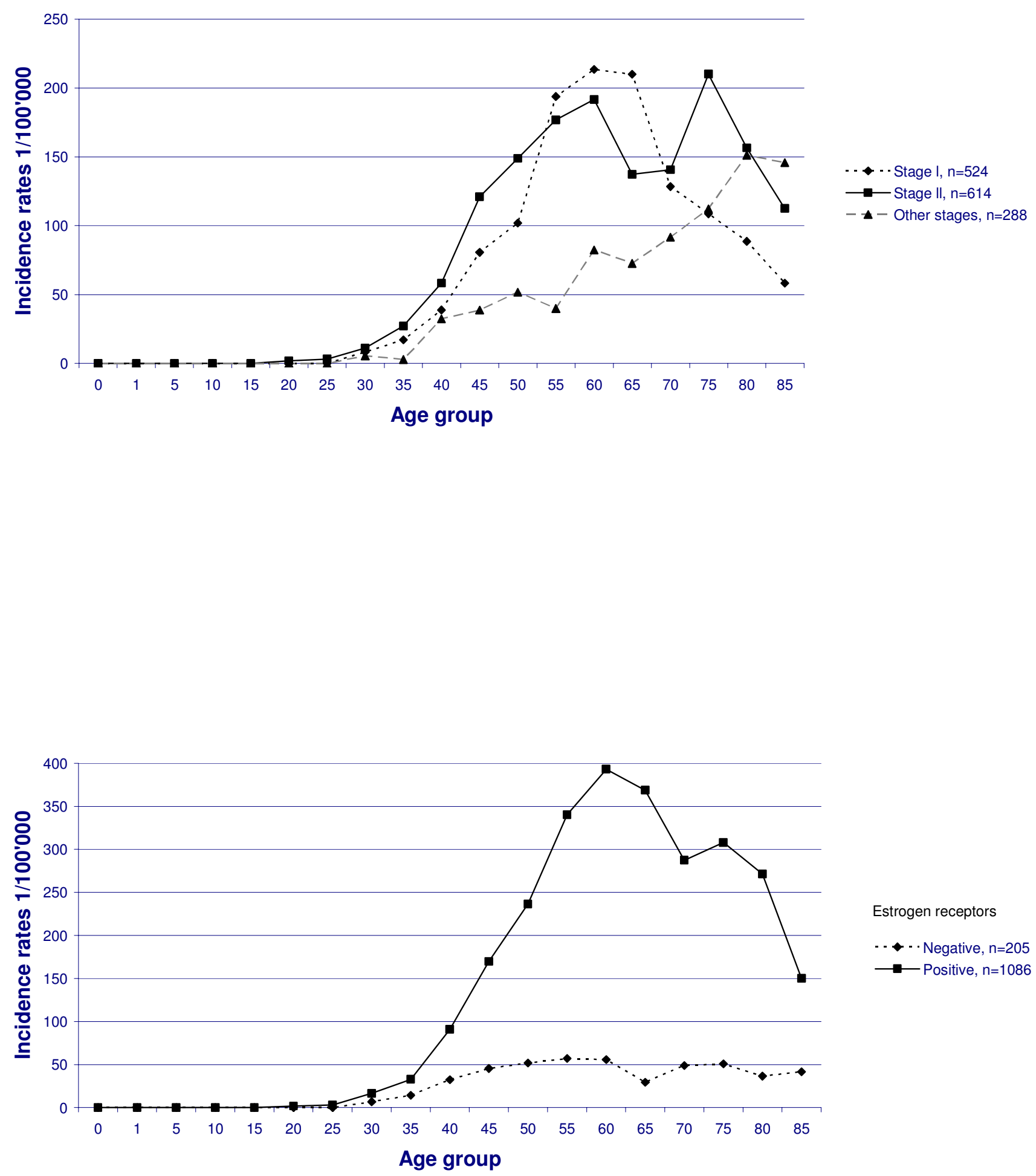

Figure 2

Invasive breast cancer incidence rates according to stage at diagnosis (panel a) and oestrogen receptor status (panel b) 19972000. Panel a. Panel b. 
Table I: Patient and tumour characteristics by period of diagnosis among patients aged 60-64 years ${ }^{1}$

\begin{tabular}{|c|c|c|c|}
\hline Patient and tumour characteristics & $1975-19791985-1989 \mathrm{~N}=218(\%)$ & $1997-2000200 \mid-2003 \mathrm{~N}=389(\%)$ & $P$ value for $X^{2}$ of heterogeneity \\
\hline \multicolumn{4}{|l|}{ Social class ${ }^{2}$} \\
\hline High & $8(6 \%)$ & 72 (19\%) & $P<0.0000$ \\
\hline Medium & $57(44 \%)$ & $203(52 \%)$ & \\
\hline Low & $26(20 \%)$ & $53(14 \%)$ & \\
\hline Unknown & $39(30 \%)$ & $61(16 \%)$ & \\
\hline \multicolumn{4}{|l|}{ Method of detection } \\
\hline Screening & $31(14 \%)$ & 199 (51\%) & $P<0.0000$ \\
\hline Other & $187(86 \%)$ & $190(49 \%)$ & \\
\hline \multicolumn{4}{|l|}{ Stage at diagnosis } \\
\hline I & $69(32 \%)$ & $186(48 \%)$ & $P<0.0000$ \\
\hline ॥ & 95 (44\%) & $149(38 \%)$ & \\
\hline III and more & $34(16 \%)$ & 42 (11\%) & \\
\hline Unknown & $20(09 \%)$ & $12(3 \%)$ & \\
\hline \multicolumn{4}{|l|}{ Oestrogen ${ }^{3}$ receptors } \\
\hline Positive & $43(61 \%)$ & $311(80 \%)$ & $P=0.002$ \\
\hline Negative & $18(25 \%)$ & $53(14 \%)$ & \\
\hline Unknown & $10(14 \%)$ & $25(6 \%)$ & \\
\hline \multicolumn{4}{|l|}{ Histological type } \\
\hline Ductal & 173 (79\%) & $311(80 \%)$ & $P<0.0000$ \\
\hline Lobular & $4(2 \%)$ & $53(14 \%)$ & \\
\hline Other & $41(19 \%)$ & $25(6 \%)$ & \\
\hline
\end{tabular}

I) the age in which the incidence peak was observed after 1997

2 ) the first period concerned 1985-1989 as information on the woman's last occupation was available only after 1980;

3 ) the fist period concerned the years 1995-1996 as information on oestrogen receptor status was available only from 1995.

tion-based case-control study, they might not be completely representative of all breast cancer patients. We compared them with the other 50-74 years old breast cancer patients recorded at the cancer registry and they appeared to be similar in terms of age, social class, stage distribution and tumour characteristics. Therefore, we believe that selection bias does not explain the fact that the new age distribution is only present among women who used HRT, irrespective of their mammography screening status. In addition, we have no information on the duration of HRT utilisation, on HRT cessation, or on time elapsed since the stop of HRT. It is therefore not possible to evaluate if the incidence peak occurred among current or ex-users of HRT. Also, we were not able to evaluate incidence patterns according to type of HRT.

To our knowledge, only three studies have reported important changes in age-specific breast cancer incidence [14-16]. In Marin Country, Bay area, San Francisco, Prehn et al. observed an increase in breast cancer incidence among women aged 45-64 years for the period 19911997, whereas the incidence among older and younger women remained stable [14]. They ruled out screening mammography as the most important reason, because the incidence increase involved also advanced stages and lob- ular cancers (which are difficult to detect mammographically), and because women aged 65-70 (an age-category also covered by screening) showed no incidence increase. The authors suggested HRT, frequently used by the relatively wealthy, well-educated female population of this area, as a possible explanation for the increasing breast cancer incidence among women aged 45-64. It was in this same region (Bay area) that the increase of endometrial adenocarcinoma, associated with postmenopausal oestrogen use, was particularly high [17]. More recently, Hemminki et al. also reported an important change in agespecific breast cancer incidence in Sweden [16]. They observed a strong incidence increase among women aged 50-69 years, but only a slight decrease for women older than 75 years. As this change in age-specific incidence coincided with the introduction of organised mammography screening programs, the authors attributed this incidence pattern change to mammography screening. Fuglede et al, reported on breast cancer incidence in a population of unscreened women in Denmark from 1973-2002, using data of the nationwide Danish Cancer Registry [15]. They showed that the age-specific incidence rates of breast cancer increased throughout the whole period. In addition, they observed marked changes in the age-specific incidence pattern: between 1973-1981, there 

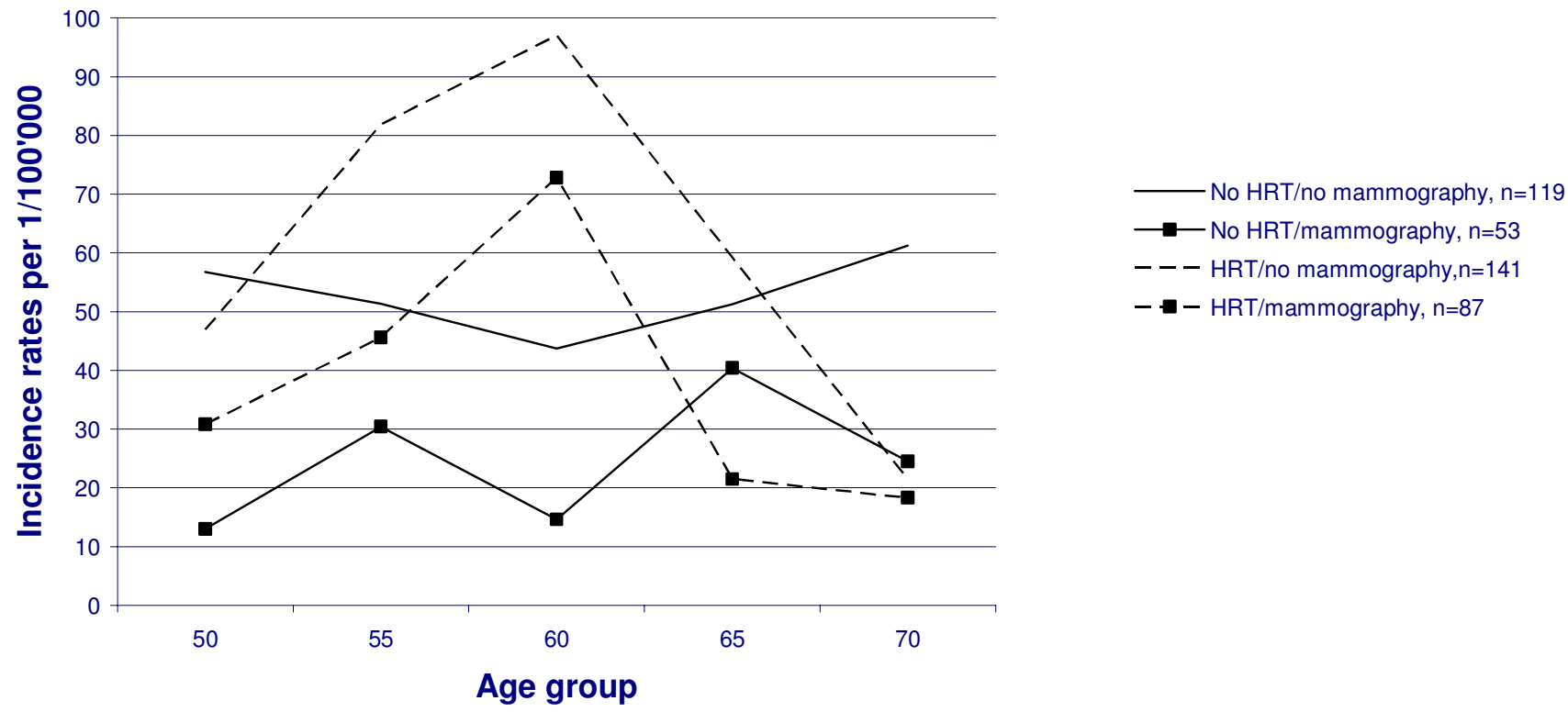

Figure 3

Invasive breast cancer incidence according to ever use of hormone replacement therapy (HRT) and detection by mammography screening, 1997-2000. As information on HRT use was available for $46 \%$ of all breast cancer patients, breast cancer incidence rates are approximately half of the overall breast cancer incidence rates during the period 1997-2000.

was a plateau and change of slope around the age of 4648 , which shifted to 64-66 years in 1994-2002. This was not due to screening as they confined their study to a nonscreened population

[15].

In our population, we believe that both HRT and, to a lesser extent, mammography screening explain the change in incidence pattern. Mammography screening advances diagnosis by detecting breast cancer at an early pre-clinical stage. This can explain why the change in pattern concerned mainly the early stages. In this study however, we did not observe the typical incidence peak among never users of HRT with screen-detected tumours. In fact, only ever users of HRT showed an incidence peak at 60-64 years, regardless whether the tumour was screen-detected or not.

It has been suggested that HRT particularly increases the risk of oestrogen receptor positive tumours [18]. In our study, the changed incidence pattern involved only women with oestrogen receptor positive tumours, which supports our hypothesis of a potential effect of HRT use on the change in age-specific breast cancer risk.

Recent studies showed that current users of HRT are at increased risk of developing breast cancer [5, 19]. These studies generally involved patients between 50-65 years and the effect of ever use of HRT on breast cancer inci- dence among elderly women (aged $\geq 75$ years) has, to our knowledge, never been examined.

Our results suggest that HRT use might not only increase breast cancer risk among middle-aged women. It may also bring forward the clinical appearance of breast cancer by several years by stimulating the growth of oestrogen sensible lesions and by inhibiting spontaneous slow down of tumours when sex hormone levels drop during menopause. This hypothesis is supported by a previous study, which showed that postmenopausal women using HRT were on average five years younger upon breast cancer diagnosis than never users [20].

Use of HRT could have eliminated the temporary protective effect of menopausal oestrogen depletion.

\section{Conclusion}

The results of this study suggest that HRT may not only increase the breast cancer risk among middle-aged women, but that it may also bring forward the clinical appearance of breast cancer. To get more insight in the complex relationship between age-specific breast cancer incidence, mammography screening and HRT, it could be useful to perform international comparisons of cancer registry data covering populations with different mammography screening policies and different prevalences of HRT use. The change in incidence pattern could have an 
impact on breast cancer mortality. If the increase is "only" anticipation in age at onset, we can expect that the subsequent mortality will remain stable. However, there is also an anticipation of stage and that could lead to a future lowered mortality. If it is a true increase in risk, then we can expect a subsequent possible increase in mortality.

\section{Competing interests}

The author(s) declare that they have no competing interests.

\section{Authors' contributions}

Christine Bouchardy, Alfredo Morabia, Helena M. Verkooijen, Gérald Fioretta and Peter Schäfer designed the study. Alfredo Morabia, Yves Wespi, Gérald Fioretta and Peter Schäfer were involved in data collection. Christine Bouchardy, Gérald Fioretta and Helena M. Verkooijen performed the statistical data analyses. All authors were involved in the interpretation of the data. All authors read and approved the final manuscript.

\section{Acknowledgements}

The authors thank Stina Blagojevic for her technical help and editorial assistance.

Helena M. Verkooijen was financially supported by PROSPER grant No 3233-069350 from the Swiss National Science Foundation.

\section{References}

I. Beral V: Breast cancer and hormone-replacement therapy in the Million Women Study. Lancet 2003, 362:419-427.

2. MacMahon B: Epidemiology and the causes of breast cancer. Int J Cancer 2006, I I 8:2373-8.

3. Hormonal contraception and post-menopausal hormonal therapy. Edited by: (IARC) I. Lyon, International Agency for Research on Cancer; 1999.

4. Risks and benefits of estrogen plus progestin in healthy postmenopausal women: principal results From the Women's Health Initiative randomized controlled trial. JAMA 2002, 288:32I-333.

5. de Jong-van den Berg LT, Faber A, van den Berg PB: HRT use in $200 \mathrm{I}$ and 2004 in The Netherlands-A world of difference. Maturitas 2005.

6. Stefanick ML: Estrogens and progestins: background and history, trends in use, and guidelines and regimens approved by the US Food and Drug Administration. Am J Med 2005, I I 8:64-73.

7. Cancer Incidence in Five Continents Vol. VII. Edited by: Parkin DM, Whelan SL, Ferlay J, Raymond L and Young J. Lyon, International Agency for Research on Cancer; 1997.

8. Wanner P, Raymond L, Bouchardy C: Geographical disparities in self-reported use of mammography and breast self-examination according to the Swiss Health Survey. Ann Oncol 200I, I 2:573-574.

9. Schaad MA, Bonjour JP, Rizzoli R: Evaluation of hormone replacement therapy use by the sales figures. Maturitas 2000 , 34:|85-19|.

10. TNM Classification of malignant tumours. 4th edition, 2 nd revision 4 th edition. Edited by: (UICC) IUC. Berlin, Springer Verlag; 1992.

II. Morabia A, Bernstein MS, Heritier S, Khatchatrian N: Relation of breast cancer with passive and active exposure to tobacco smoke [see comments]. Am J Epidemiol 1996, 143:918-928.

12. Estève J, Benhamou E, Raymond L: Statistical methods in cancer research. Vol IV: Descriptive epidemiology. Lyon, International agency for research on cancer; 1994.
13. Prehn A, Clarke C, Topol B, Glaser S, West D: Increase in breast cancer incidence in middle-aged women during the 1990s. Ann Epidemiol 2002, I 2:476-48I.

14. Fuglede $\mathrm{N}$, Langballe $\mathrm{O}$, Svendsen $\mathrm{AL}$, Tjonneland $\mathrm{A}$, Dalton SO, Johansen C: Development in incidence of breast cancer in non-screened danish women, 1973-2002-a population-based study. Int / Cancer 2006, I I 8:2366-9.

15. Hemminki K, Rawal R, Bermejo JL: Mammographic screening is dramatically changing age-incidence data for breast cancer. J Clin Oncol 2004, 22:4652-4653.

16. Weiss NS, Szekely DR, Austin DF: Increasing incidence of endometrial cancer in the United States. N Engl J Med I976, 294: $1259-1262$.

17. Chen CL, Weiss NS, Newcomb P, Barlow W, White E: Hormone replacement therapy in relation to breast cancer. JAMA 2002, 287:734-74I.

18. Bilimoria MM, Winchester DJ, Sener SF, Motykie G, Sehgal UL, Winchester DP: Estrogen replacement therapy and breast cancer: analysis of age of onset and tumor characteristics. Ann Surg Oncol 1999, 6:200-207.

\section{Pre-publication history}

The pre-publication history for this paper can be accessed here:

http://www.biomedcentral.com/1471-2407/6/78/prepub
Publish with Biomed Central and every scientist can read your work free of charge

"BioMed Central will be the most significant development for disseminating the results of biomedical research in our lifetime. "

Sir Paul Nurse, Cancer Research UK

Your research papers will be:

- available free of charge to the entire biomedical community

- peer reviewed and published immediately upon acceptance

- cited in PubMed and archived on PubMed Central

- yours - you keep the copyright
BioMedcentral 